\title{
LA-UR-15-27611
}

Approved for public release; distribution is unlimited.

Title: Isolator fragmentation and explosive initiation tests

Author(s):

Dickson, Peter

Rae, Philip John

Foley, Timothy J.

Novak, Alan M.

Armstrong, Christopher Lee

Baca, Eva V.

Gunderson, Jake Alfred

Intended for: $\quad$ Report

Issued:

2015-09-30 
Disclaimer:

Los Alamos National Laboratory, an affirmative action/equal opportunity employer,is operated by the Los Alamos National Security, LLC for the National NuclearSecurity Administration of the U.S. Department of Energy under contract DE-AC52-06NA25396. By approving this article, the publisher recognizes that the U.S. Government retains nonexclusive, royalty-free license to publish or reproduce the published form of this contribution, or to allow others to do so, for U.S. Government purposes. Los Alamos National Laboratory requests that the publisher identify this article as work performed under the auspices of the U.S. Departmentof Energy. Los Alamos National Laboratory strongly supports academic freedom and a researcher's right to publish; as an institution, however, the Laboratory does not endorse the viewpoint of a publication or guarantee its technical correctness. 


\section{Isolator fragmentation and explosive initiation tests}

Peter Dickson, Philip Rae, Tim Foley, Alan Novak, Chris Armstrong, Eva Baca, Jake Gunderson.

\section{Summary}

Three tests were conducted to evaluate the effects of firing an isolator in proximity to a barrier or explosive charge. The tests with explosive were conducted without a barrier, on the basis that since any barrier will reduce the shock transmitted to the explosive, bare explosive represents the worst-case from an inadvertent initiation perspective. No reaction was observed.

The shock caused by the impact of a representative plastic material on both bare and cased PBX 9501 is calculated in the worst-case, 1-D limit, and the known shock response of the HE is used to estimate minimum run-to-detonation lengths. The estimates demonstrate that even 1-D impacts would not be of concern and that, accordingly, the divergent shocks due to isolator fragment impact are of no concern as initiating stimuli.

\section{Test Configurations and Results}

\section{Barrier Test Setup}

An isolator was test fired mounted in a $1 / 16$ inch aluminum plate inside a 5 inch diameter, $3 / 8$ inch thick, aluminum cylinder, viewed axially to the cylinder with a Shimadzu HPV2 high-speed framing camera running at 0.5 . Focused, rear flash illumination was used to observe fragments and provide shadowgraph images of the blast wave and other air shocks.

\section{Barrier Test Results}

The 0.5 Mfps high-speed sequence shows an air shock, followed by reaction products and fragmented case material from the top section of the device. Figure 1 shows selected images from the Shimadzu high-speed sequence, at $10 \mu \mathrm{s}$ intervals. Analysis of the images indicates that the initial air shock is moving at just over $1 \mathrm{~km} \mathrm{~s}^{-1}$, and that the maximum epoxy fragment velocity is around $800 \mathrm{~m} \mathrm{~s}^{-1}$.

All other parts of the device move very slowly in comparison, due to higher density and being less coupled to the driving explosive, and were recovered mostly intact as seen in figure 2 . As expected, the event is not particularly violent, and the enclosing aluminum cylinder sustained just a few minor dents (figure 3) since the fragments produced by firing the isolator are much too slow and low density to result in any significant penetration depth. Figure 4 shows the mass distribution of the recovered fragments from the epoxy shell, but note that many of the smallest fragments were not recovered. 


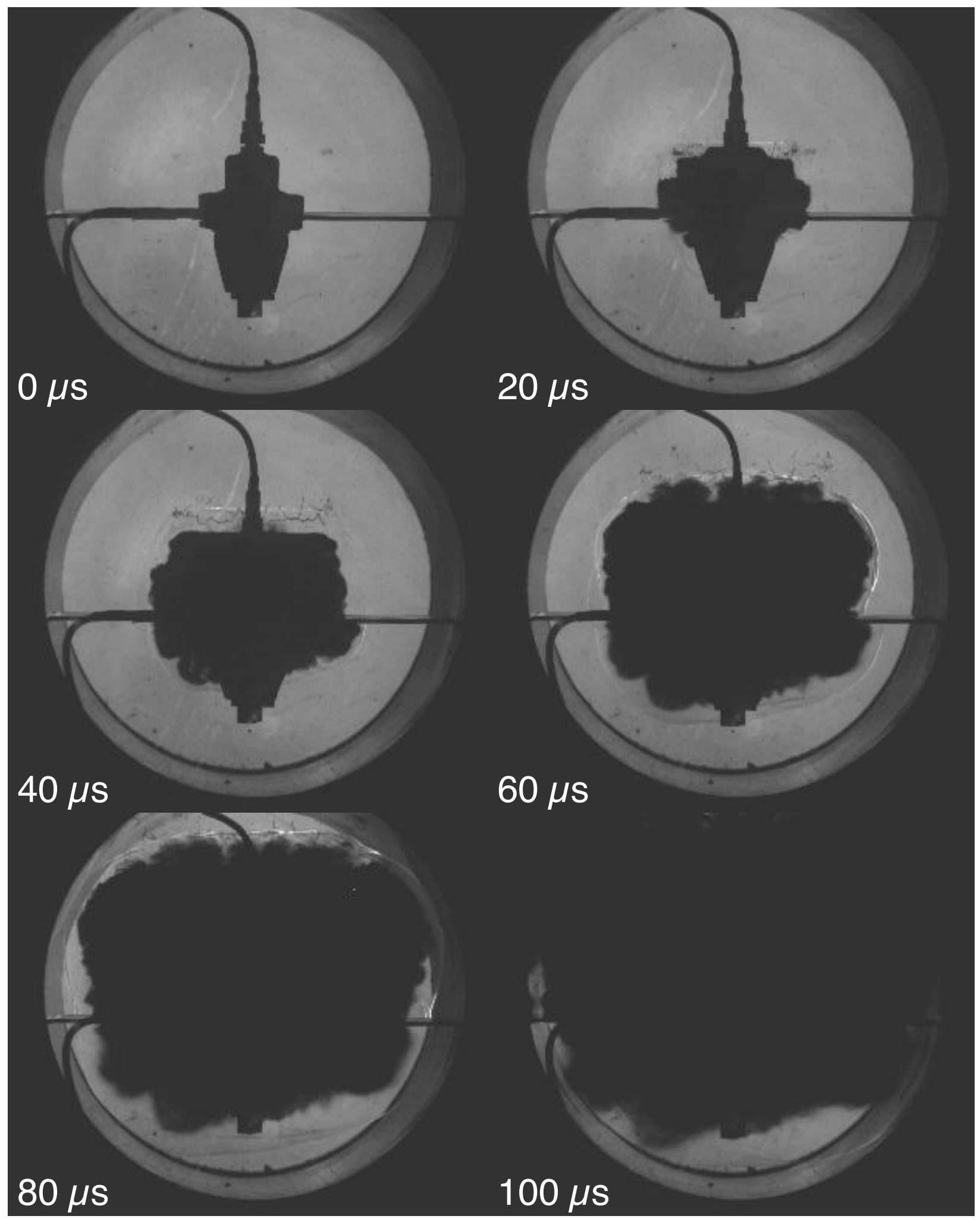

Figure 1. High-speed images of isolator test fired in 5-inch tube (Shimadzu HPV2). 

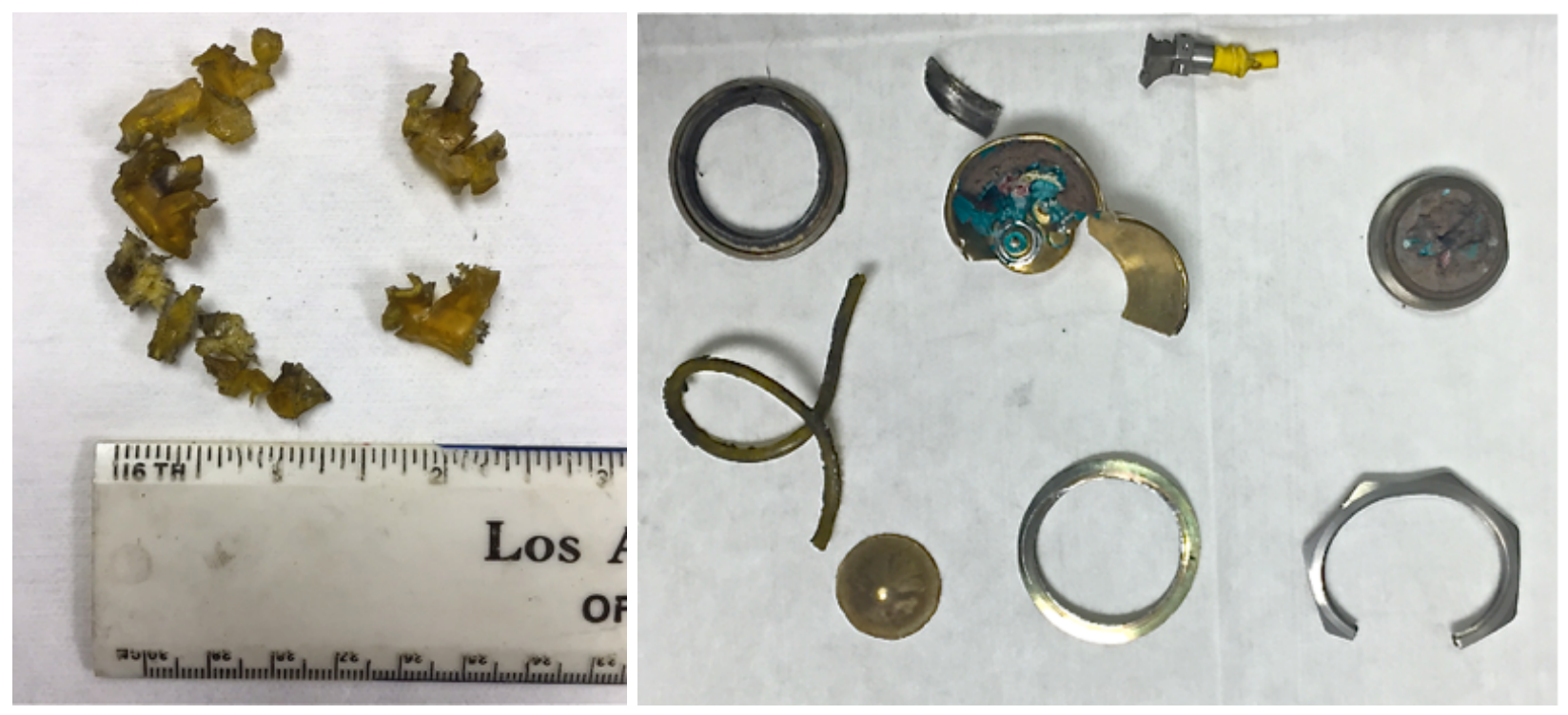

Figure 2. Plastic fragments and remaining parts.

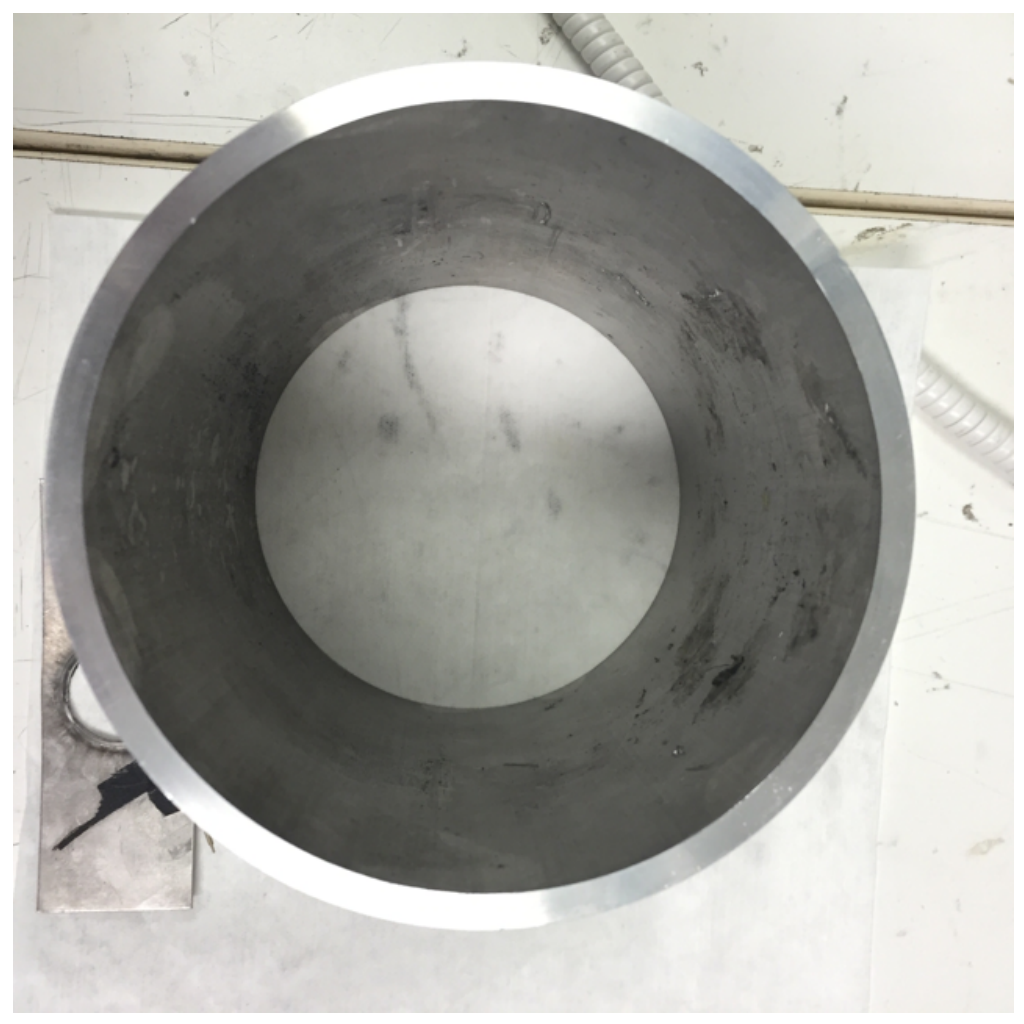

Figure 3. Aluminum tube after test shot. 


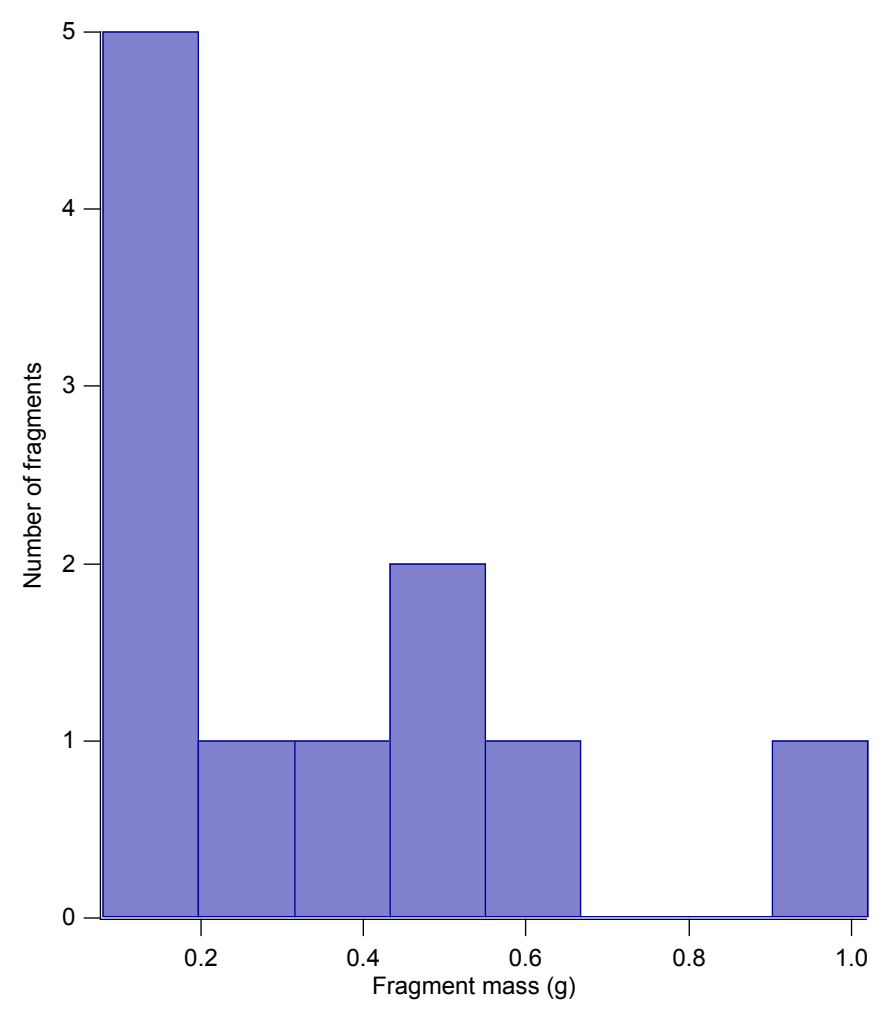

Figure 4. Recovered fragments mass distribution.

\section{Explosive Initiation Test Setup}

Two tests were performed in which an isolator was detonated adjacent to an acceptor charge of PBX 9501. The first test was conducted with a standoff distance of 1 inch, while in the second test the isolator was in direct contact with the explosive.

As with the penetration tests, the shots were recorded with a Shimadzu HPV2 high-speed framing camera running at $0.5 \mathrm{Mfps}$ with focused, rear flash illumination.

\section{Explosive Initiation Test Results}

Neither test resulted in any reaction in the explosive acceptor. Figure 5 shows images from the high-speed sequence of the 1-inch standoff test, and figure 6 shows similar images from the direct contact test.

With the 1-inch standoff, the acceptor charge was disturbed, but not cracked (figure 7). Surface damage and cracking was observed in the direct contact test (figure 8). 


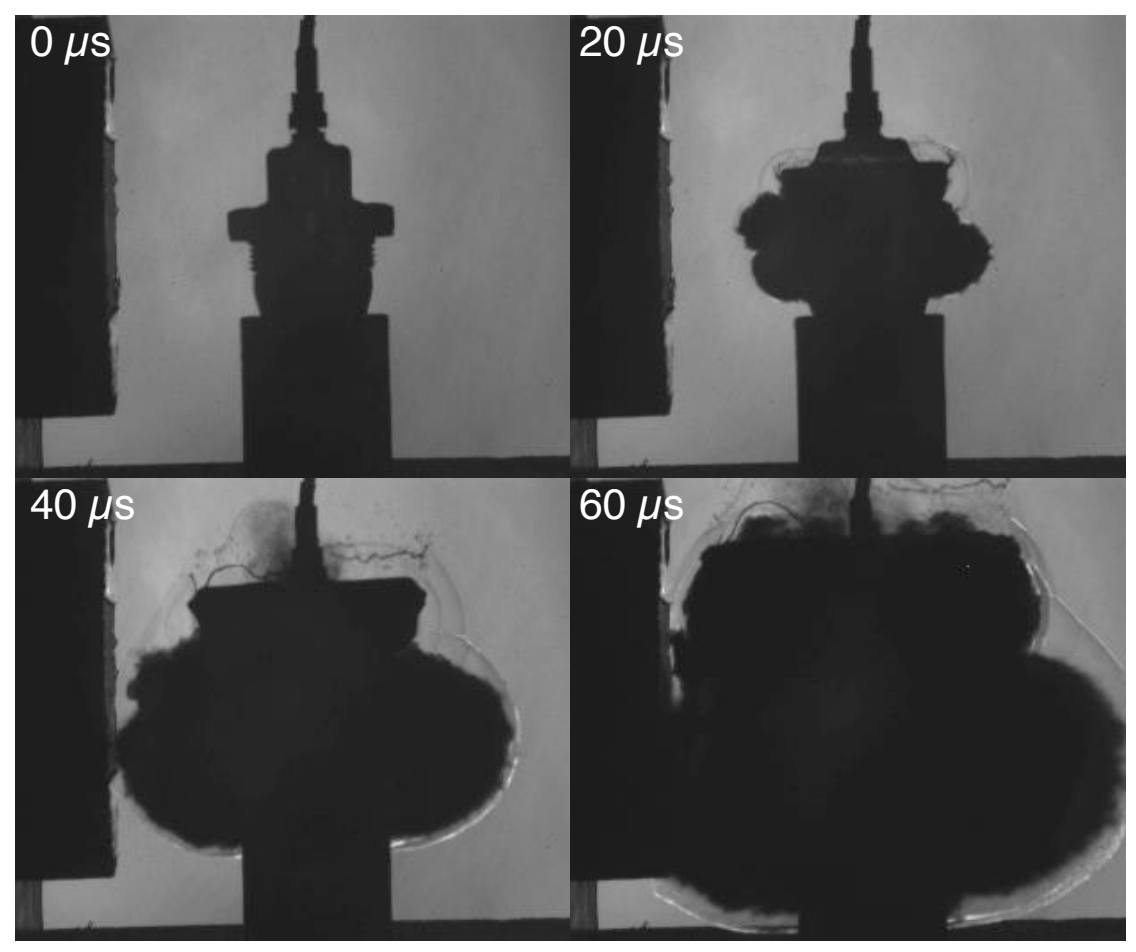

Figure 5. High-speed images from 1-inch standoff test.

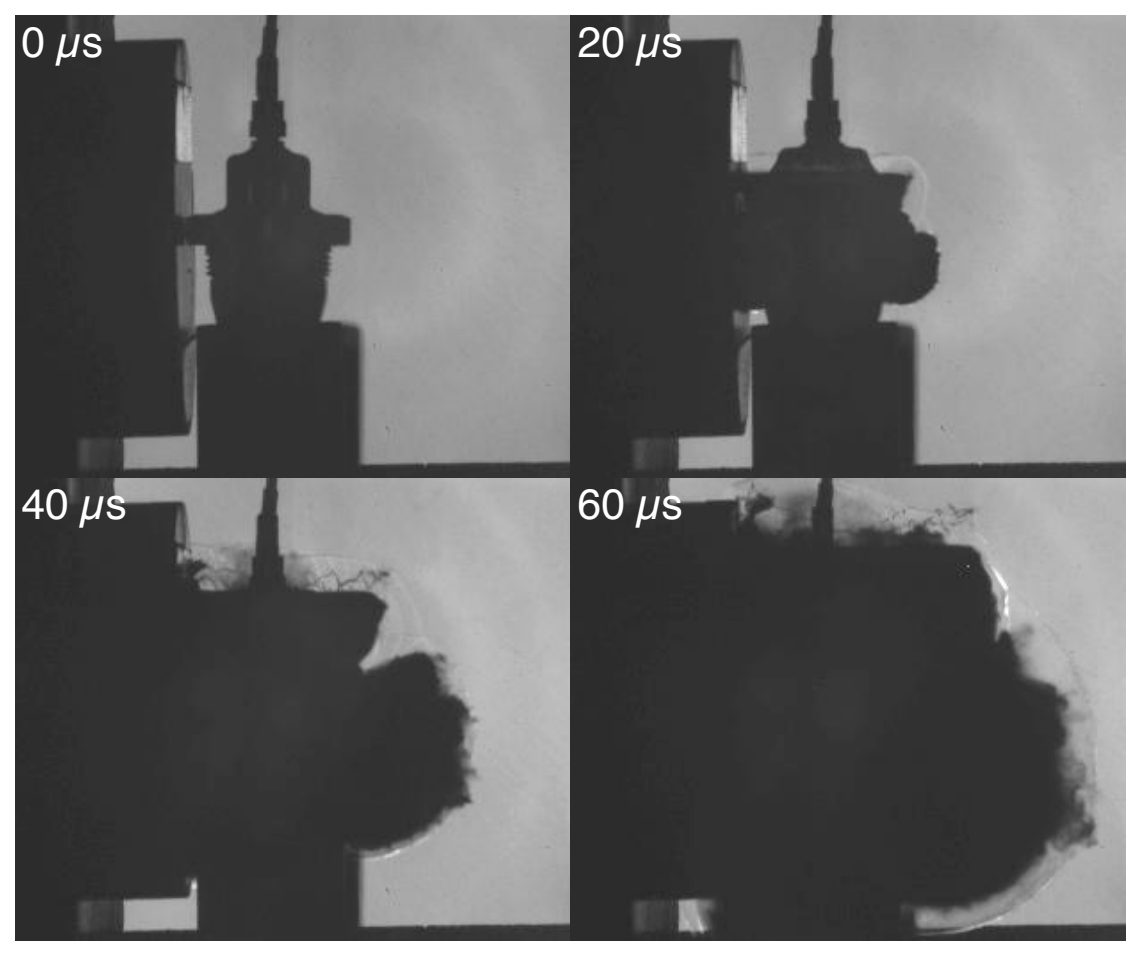

Figure 6. High-speed images from direct contact test. 

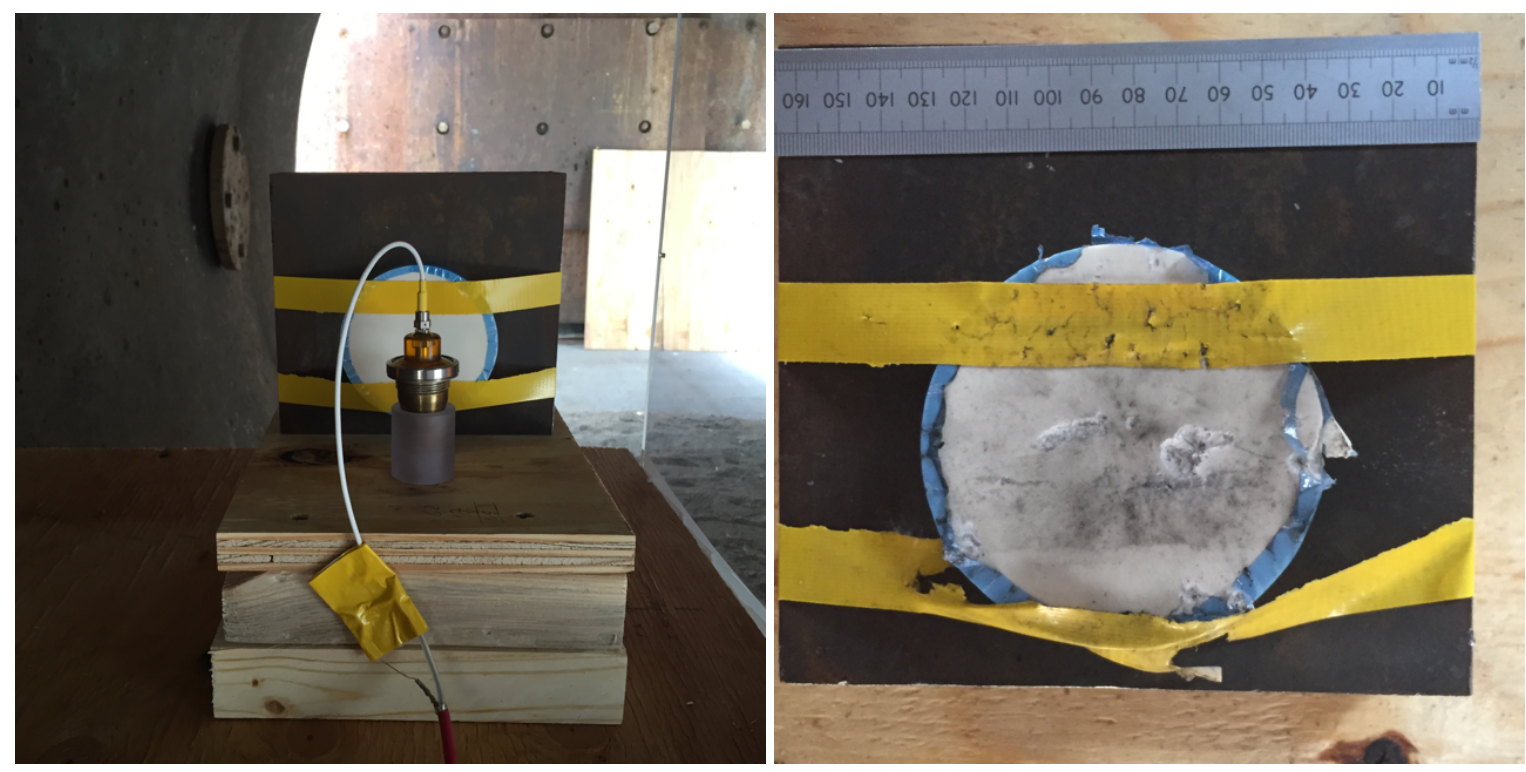

Figure 7. 1 inch standoff test and resulting damage.
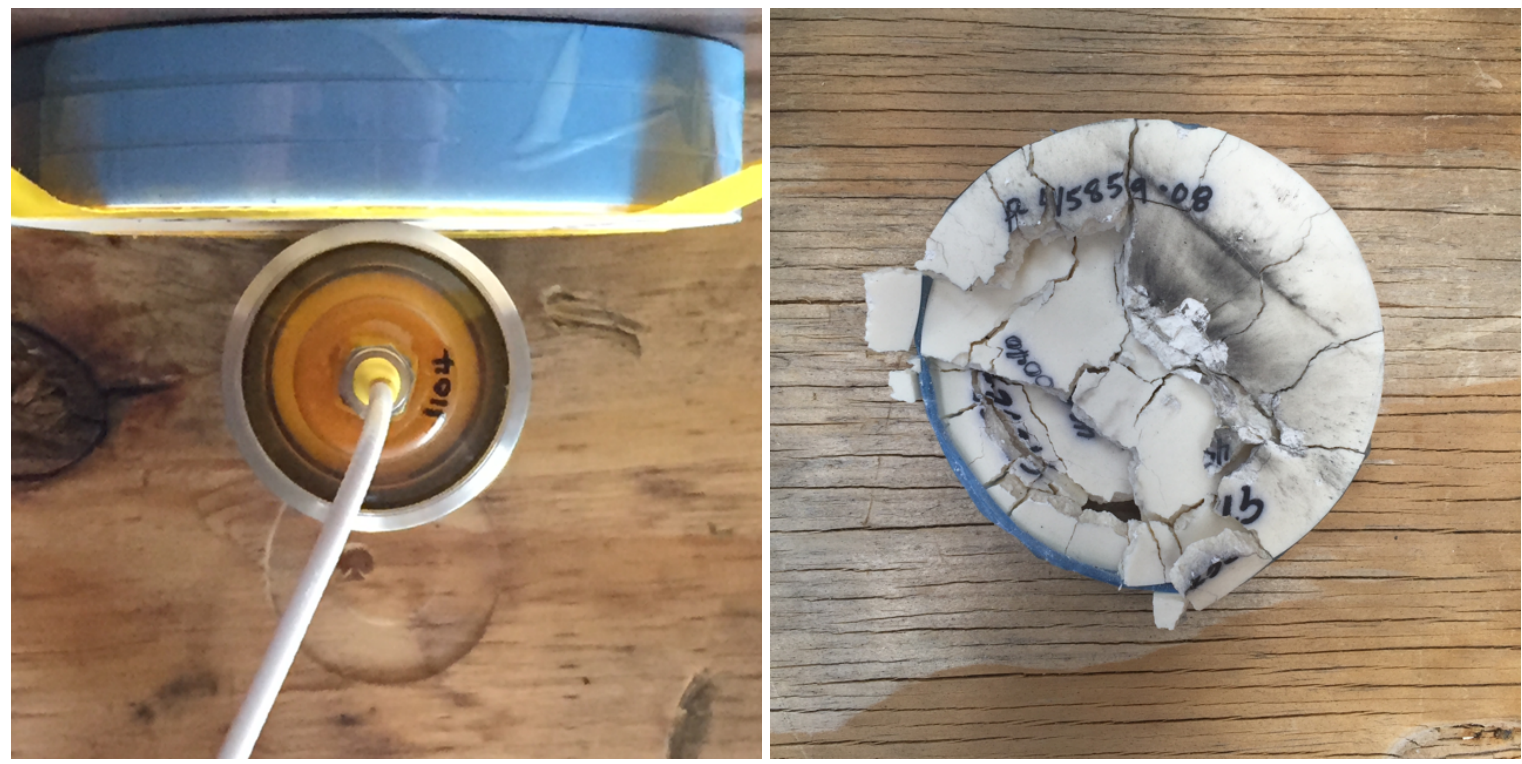

Figure 8. Direct contact test and resulting damage. 


\section{Impact Shock and Run-to-Detonation Length Calculations}

Impacting PBX 9501 with fragmented plastic does not produce an effective initiating shock wave, and so we may conservatively bound the problem by considering, instead, the impact of a thick, planar flier of the same material. In such a case, shock matching allows us to calculated the transmitted shock pressures ${ }^{1}$ which, together with the known 1-D shock initiation behavior of PBX 9501², permits us to estimate the resulting run-to-detonation length as a function of impact velocity.

Figure 9 shows the calculated transmitted uniaxial shock pressure due to the supported, 1D impact of a representative epoxy onto both bare and cased PBX 9501, as a function of impact velocity.

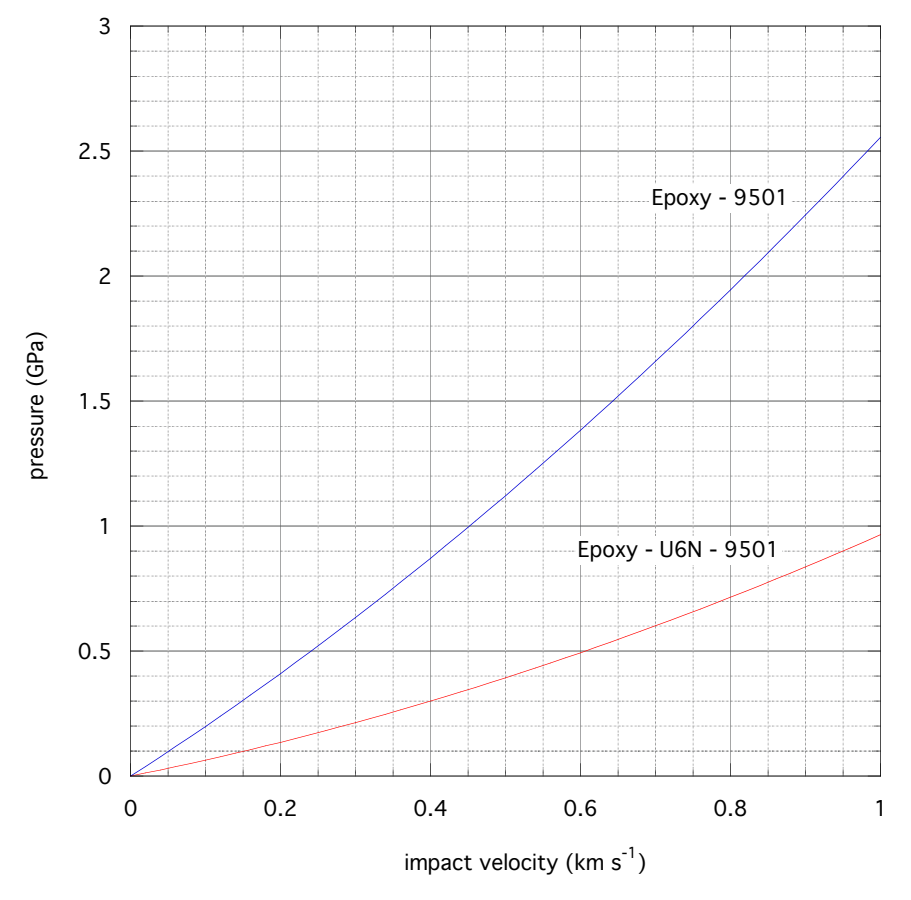

Figure 9. Calculated 1-D pressure in PBX 9501.

Figure 10 shows the calculated run-to-detonation lengths expected in PBX 9501 as a result of these input shock pressures, with and without a casing.

For bare PBX 9501 we find that a planar $800 \mathrm{~m} \mathrm{~s}^{-1}$ impact should transit to detonation after a run distance of $12 \mathrm{~mm}$. Note that in addition to the requirement of a 1-D impact, 
rarefaction wave considerations associated with this initiation event would also require the epoxy flier to be more than $12 \mathrm{~mm}$ in diameter.

Repeating the calculation, with the addition of a U6N barrier, leads to a run-to-detonation length of $32 \mathrm{~mm}$ for an $800 \mathrm{~m} \mathrm{~s}^{-1}$ impact. This result is outside the applicability of the POPplot data for PBX 9501, and probably represents a no-go even if these conditions are met. In any case, it would require a 1-D epoxy fragment over $32 \mathrm{~mm}$ in diameter to meet these criteria.

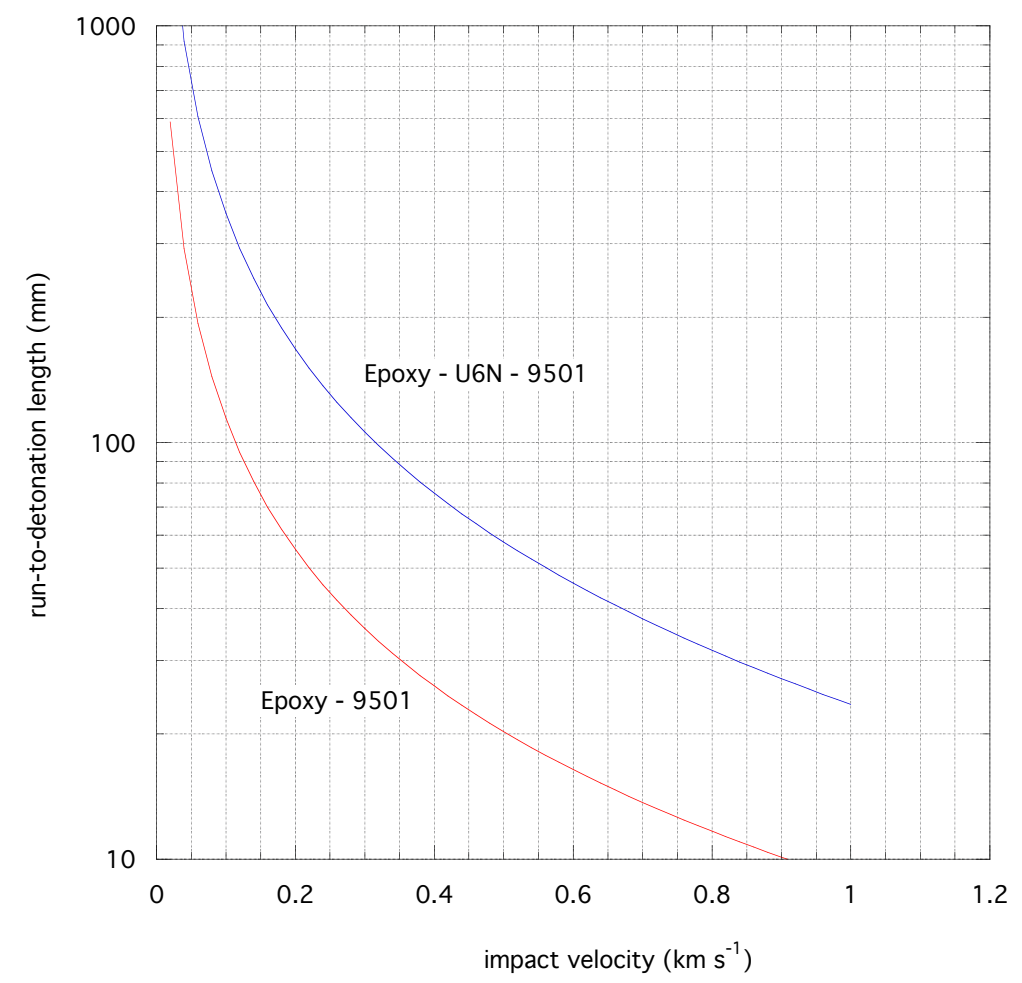

Figure 10. Calculated run-to-detonation length with and without a casing. 


\section{Conclusions}

The fragmented plastic/epoxy shell is moving quite fast, but is low density. Even a 1-D flier of that material would lead to a substantial run-to-detonation length in PBX 9501;

rubbleized material will cause short, divergent shocks that will not cause initiation.

When a high-density barrier is included, the shock impedance mismatches substantially reduce the input pressure to the PBX 9501 (figure 5) and result in unrealistically long runto-detonation lengths even in the 1-D case, while the hazard from the actual fragment field becomes insignificant.

\section{References}

1. Marsh, S.P. (Ed.), LASL Shock Hugoniot Data, University of California Press, Berkeley (1980).

2. Gibbs, T.R. and Popolato, A. (Eds.), LASL Explosive Property Data, University of California Press, Berkeley (1980). 